\title{
Propriedade Intelectual para Inovação: percepções e perspectivas em uma escola profissionalizante
}

\author{
Intellectual Property for Innovation: perceptions and perspectives in a \\ technical school
}

\author{
Verônica Maria Vasconcelos Freire ${ }^{1}$ \\ Joelia Marques de Carvalho 2 \\ ${ }^{1}$ Instituto Federal de Educação, Ciência e Tecnologia do Ceará, Fortaleza, CE, Brasil \\ ${ }^{2}$ Instituto Federal de Educação, Ciência e Tecnologia do Ceará, Caucaia, CE, Brasil
}

\begin{abstract}
Resumo
O ensino de conteúdos relacionados à inovação e à propriedade intelectual é determinante para a formação de profissionais aptos a atuar no contexto da economia do conhecimento. Este artigo retrata as principais conclusões de uma pesquisa exploratória que examinou se essa temática é abordada em cursos técnicos no nível médio do Instituto Federal do Ceará, Campus Caucaia. Por meio de questionários com alunos, entrevistas semiestruturadas com professores e análise de projetos pedagógicos, foram observados aspectos favoráveis, necessidades e barreiras para o ensino de tais conteúdos. Entre os resultados, o estudo demonstrou que os professores não apenas consideram relevante a inclusão da temática nas atividades educativas, como também defendem a ampliação do investimento na capacitação docente para melhorar os níveis dessas atividades. Os resultados revelam, ainda, informações úteis para aprimorar o planejamento de ações pedagógicas e para a realização de novos estudos sobre o tema.
\end{abstract}

Palavras-chave: Ensino de inovação. Formação para o Trabalho. Propriedade Intelectual.

\begin{abstract}
The teaching of content related to innovation and intellectual property is crucial for the training of professionals able to work in the context of the knowledge economy. This article portrays the main conclusions of an exploratory research that examined whether this theme is addressed in technical courses at the high level of the Federal Institute of Ceará - Campus Caucaia. Through questionnaires with students, semi-structured interviews with teachers and analysis of pedagogical projects, favorable aspects, needs and barriers for teaching such content were observed. Among the results, the study showed that teachers not only consider the inclusion of the theme in educational activities relevant, but also defend the expansion of investment in teacher training to improve the levels of these activities. The results also reveal useful information to improve the planning of pedagogical actions, as well as to carry out new studies on the topic.
\end{abstract}

Keywords: Innovation Teaching. Training for work. Intellectual Property.

Área Tecnológica: Inovação. Transferência de Tecnologia. Educação. 


\section{Introdução}

A ampla democratização do conhecimento sobre inovação, Propriedade Intelectual (PI) e empreendedorismo é determinante para a formação de profissionais preparados para atuar no cenário da economia do conhecimento. Em 2019, o Brasil ficou em $66^{\mathrm{a}}$ posição no Índice Global de Inovação de 2019 (IGI), caindo duas posições em relação ao ano de 2018 (OMPI, 2019). Para melhorar o índice, é fundamental que os cidadãos compreendam como o sistema de propriedade intelectual protege as criações do espírito humano, permitindo sua conversão em propriedade privada.

Um dos públicos prioritários, nesse contexto, são os estudantes em formação na rede de educação profissional e tecnológica. Esses futuros profissionais estarão na linha de frente das empresas brasileiras e precisarão resolver problemas com soluções criativas - um perfil profissional adaptado a empresas inovadoras. Ademais, a Educação Profissional e Tecnológica (EPT) é uma modalidade educacional prevista na Lei de Diretrizes e Bases da Educação Nacional (LDB) com a finalidade precípua de preparar "[...] para o exercício de profissões [...]" (BRASIL, 1996). Ou seja, uma modalidade que mantém estreita relação com mundo do trabalho e, consequentemente, do empreendedorismo e da inovação.

A necessidade de formação de recursos humanos para a inovação é reconhecida pela Lei n. 13.243, sancionada em 11 de janeiro de 2016, quando se refere às Instituições de Ciência e Tecnologia (ICT) de Direito Público. A Lei prevê que as políticas de inovação das ICTs estabeleçam as diretrizes e os objetivos para capacitação em empreendedorismo, gestão da inovação, transferência de tecnologia e propriedade intelectual (BRASIL, 2016).

Ao se observar o Instituto Federal do Ceará (IFCE), percebe-se que a instituição mantém ativa atuação em inovação tecnológica. $\mathrm{O}$ instituto ficou em terceira posição entre as instituições que mais depositaram pedidos de patentes no Instituto Nacional de Propriedade Intelectual (INPI), entre os anos de 2009 e 2017. A pesquisa identificou, ao todo, 307 depósitos de pedidos. O IFCE registrou 45 pedidos no período, ficando atrás da Universidade Federal do Ceará (215) e da Universidade Estadual do Ceará (46) (ARAÚJO et al., 2018); o que demonstra um resultado relevante no contexto estadual.

Outro fato que reforça a atuação do IFCE no campo da inovação é a existência, desde 2002, do Laboratório de Inovação Tecnológica (LIT), concebido para aproximar o setor produtivo das áreas de energia elétrica, tecnologia da informação e telecomunicações com o setor acadêmico, assim desenvolvendo e inovando os setores de tecnologia do mercado.

Desde 2014, o IFCE sedia o Polo de Inovação da Empresa Brasileira de Pesquisa e Inovação Industrial (EMBRAPII) em Fortaleza, para atuar nas áreas de competência de mobilidade digital e sistemas embarcados. Esses polos buscam interação entre as cadeias produtivas da indústria com a pesquisa, desenvolvimento e inovação (PD\&I) e atuam também como apoio à formação profissional dos setores de base tecnológica.

Além disso, o IFCE é um dos polos do Mestrado Profissional em Propriedade Intelectual e Transferência de Tecnologia para Inovação (Profnit). Um Programa de Pós-Graduação stricto sensu mantido pela Associação Fórum Nacional de Gestores de Inovação e Transferência de Tecnologia (FORTEC), dedicado ao aprimoramento da formação profissional para atuar nas competências dos Núcleos de Inovação Tecnológica e em ambientes promotores de inovação. 
Pelo perfil dos IFCE e pela legislação envolvida na promoção da inovação no Brasil, considera-se pertinente que no âmbito do instituto as iniciativas de gestão da inovação e propriedade intelectual transbordem, em forma de conhecimento, para todo o universo dos corpos docente e discente, o que, consequentemente, resultará em um precioso diferencial para os estudantes.

Diante dessa realidade, este estudo tem como objetivo geral observar se as ações implementadas para a adequação dos Institutos Federais (IFs) ao modelo de inovação brasileiro repercutiram nas práticas de ensino em cursos técnicos no nível médio profissionalizante do IFCE Campus Caucaia.

Como objetivos específicos de pesquisa, buscou-se analisar a inclusão dos conteúdos nos projetos pedagógicos de cursos técnicos oferecidos na Região Metropolitana de Fortaleza; verificar o acesso de estudantes aos conteúdos e identificar aspectos que, na visão dos professores, deveriam fazer parte do processo de ensino para estimular o desejo e o gosto pelo estudo acerca de inovação tecnológica e propriedade intelectual. Por fim, objetivou-se também comparar os resultados com os obtidos por outros três estudos sobre o ensino de propriedade intelectual.

\subsection{O Ensino de Propriedade Intelectual para a Inovação}

Os conceitos de inovação e propriedade intelectual estão intimamente ligados. O sistema de PI permite que conhecimentos, invenções, obras literárias e artísticas sejam protegidas e convertidas em propriedade privada.

A convenção da Organização Mundial da Propriedade Intelectual (OMPI) define como propriedade intelectual a soma dos direitos relativos às obras literárias, artísticas e cientificas, às interpretações dos artistas intérpretes e às execuções dos artistas executantes, aos fonogramas $e$ às emissões de radiodifusão, às invenções em todos os domínios da atividade humana, às descobertas científicas, aos desenhos e modelos industriais, às marcas industriais, comerciais e de serviço, bem como às firmas comerciais e denominações comercias, à proteção contra a concorrência desleal e todos os outros direitos inerentes à atividade intelectual nos domínios industrial, científico, literário e artístico.

Uma economia voltada para ciência, tecnologia e inovação fomenta a competitividade, o surgimento de novos empreendimentos, empregos e marcas comerciais. Essa estratégia, por sua vez, tende a aumentar a interação entre política industrial e tecnológica e propriedade intelectual (KRUGLIANSKAS; MATIAS-PEREIRA, 2005).

Os conceitos de PI e inovação refletem um campo de conhecimento intrinsecamente associado ao modelo econômico da sociedade contemporânea. Além de úteis para os diversos entes que integram o Sistema Nacional de Inovação, tais conhecimentos podem agregar vantagem para o cidadão comum, uma vez que qualquer pessoa pode criar obras, produzir conhecimento e gerar ativos intangíveis (FARIA, 2011).

Durante muito tempo, contudo, o ensino de PI ficou restrito aos cursos de direito. Essa realidade mudou com a globalização e a economia do conhecimento, que consagraram a PI como questão relacionada ao comércio (TAKAGI; ALLMAN; SINJELA, 2008). De fato, a PI passou a se relacionar intimamente aos negócios e à competitividade após a criação da Organização Mundial do Comércio com o Agreement on Trade-Related Aspects of Intellectual Property Rights (TRIPS). 
Questões de propriedade intelectual passaram a interessar para a sociedade, em assuntos como a biopirataria, o patenteamento de células-tronco, entre outros temas (AMORIM-BORHER et al., 2007). Entende-se vantajosa a democratização dessas informações e conhecimentos para diferentes públicos.

Para Takagi, Allman e Sinjela (2008, p. 3), "Estudantes de uma ampla variedade de disciplinas, incluindo administração, direito, artes, engenharia, ciências e jornalismo, poderiam se beneficiar da propriedade intelectual".

Os mesmos autores defendem o ensino da temática para crianças. Entre os argumentos, eles destacam que "Uma introdução à Propriedade Intelectual efetiva e interessante permite que as crianças vejam como sua criatividade pode conduzi-las e como seus sonhos e imaginações podem resultar em produtos e serviços reais" (TAKAGI; ALLMAN; SINJELA, 2008, p. 9).

Os autores argumentam, ainda, que o ensino de PI para crianças justifica-se por ensinar o respeito à originalidade dos trabalhos delas próprias e das outras pessoas, bem como oferece lições sobre como o poder do intelecto, da inventividade e da criatividade pode contribuir para a sustentabilidade da economia.

A educação dos jovens na temática pode ser considerada útil em dois aspectos principais: mostrar a importância do respeito às criações alheias e promover a busca pela criatividade, enfatizando o valor social e econômico de uma mente criativa (WIPO, 2013).

O Reino Unido e o Japão são exemplos de países que empreenderam iniciativas para educar os alunos das escolas primárias e secundárias sobre aspectos relacionados à PI. Na Alemanha, algumas lições introdutórias são ministradas nas escolas secundárias por oradores convidados, profissionais da propriedade intelectual, como iniciativa privada de professores individuais (WIPO, 2013).

Um dos projetos estruturantes do Escritório Estadual de Propriedade Intelectual da República Popular da China (CNIPA-CHINA) diz respeito à democratização dos conceitos de PI. O documento está disponível na página de colaboração dos escritórios de propriedade intelectual dos países membros dos BRICS (coordenação entre Brasil, Rússia, Índia, China e África do Sul).

Uma das ações foi a edição de livros especializados com foco na conscientização pública e no ensino nas escolas de níveis fundamental e médio. De 2013 a 2017, a Editora da Propriedade Intelectual da China publicou mais de 700 livros. Em 2017, a CNIPA encomendou manuais nacionais de demonstração de educação em PI para alunos do ensino fundamental e médio e uma série de romances e desenhos animados com o tema "Eu posso inventar" (INPI, 2019).

Amorim-Borher et al. (2007) revelam que a experiência brasileira no tocante à capacitação em Propriedade Intelectual tem sido variada e se divide em duas grandes vertentes: as de curto prazo e as de pós-graduação. A primeira reúne eventos como seminários, palestra, workshops, entre outros.

Segundo a autora, os cursos de pós-graduação foram inaugurados em 2001, com uma iniciativa de pós-graduação lato sensu em Propriedade Intelectual promovida pelo INPI em parceria com o Centro Federal de Educação Tecnológica Celso Suckow da Fonseca - Rio de Janeiro. A especialização contou com três edições, mas com a saída do INPI, foi descontinuada.

Outro curso de especialização em formato de Masters of Business Administration (MBA) de 420 horas foi lançado em 2004, com a criação do Laboratório de Ensino e Pesquisa em Inovação e Gestão da Propriedade Intelectual. Essa iniciativa também foi obra do INPI, desta 
vez em parceria com a Universidade Federal do Rio de Janeiro (UFRJ). Em 2006, o INPI criou a Academia de Propriedade Intelectual e Inovação, oferecendo programas de curta duração e mestrado profissional.

Entre as iniciativas existentes na atualidade brasileira, destaca-se o Programa de Pós-Graduação em Propriedade Intelectual e Transferência de Tecnologia para a Inovação. O programa stricto sensu tem como objetivo formar profissionais para atuar nos Núcleos de Inovação Tecnológicas e em ambientes promotores de inovação. É um programa mantido pelo Fórum Nacional de Gestores de Inovação e Transferência de Tecnologia, com pontos focais em todas as regiões do País.

Na sua atuação dentro das competências dos NITs, o mestrando deverá ter os conhecimentos básicos para o diálogo academia-empresa, estando habilitado a interagir propositivamente com os setores governamental, empresarial e acadêmico (PROFNIT, 2020).

\section{Metodologia}

Do ponto de vista dos procedimentos técnicos, trata-se de um estudo de caso que envolveu um universo de 45 participantes: 40 alunos maiores de 18 anos e cinco professores das áreas técnica e propedêutica. Do ponto de vista da forma de abordagem do problema, trata-se de uma pesquisa qualitativa. Do ponto de vista dos objetivos, a pesquisa exploratória procurou conhecer a realidade estudada, suas características, seus problemas. Posteriormente, aplicou-se o método comparativo, buscando-se similaridades e diferenças com a situação abordada, em três artigos sobre disseminação da cultura da propriedade intelectual.

O estudo foi aprovado pela Comissão Nacional de Ética em Pesquisa por meio do Parecer Consubstanciado do Comitê de Ética em Pesquisa do IFCE n. 3.754.225 e respeitou as Resoluções n. 510 (07/04/2016), n. 466 (12/09/2012) do Conselho Nacional de Saúde, que dispõem sobre ética em pesquisa com seres humanos, observando as particularidades das pesquisas em ciências humanas e sociais.

A seleção do Campus de Caucaia teve como critério a facilidade de acesso aos corpos docente e discente. Localizado na Região Metropolitana de Fortaleza, oferece cinco cursos técnicos que, em 2020, contaram com 528 alunos matriculados. Destes, 314 efetivamente em curso (PROEN/IFCE, 2020).

A pesquisa foi realizada em três etapas. A primeira consistiu em um estudo dos projetos pedagógicos de 16 cursos técnicos de nível médio do total de 30 oferecidos nos campi da Região Metropolitana de Fortaleza (RMF). Durante a leitura do material, foram procurados oito termos do campo lexical da inovação: inovação, criatividade, invenção, desenvolvimento tecnológico, propriedade intelectual, patente, transferência de tecnologia e empreendedorismo.

Esta primeira abordagem de investigação levou em consideração a definição de projeto político-pedagógicos de Longhi e Bento (2006). Para os autores, o documento facilita e organiza as atividades, além de mediar decisões e conduzir ações para a futuro com base na sua realidade atual e sua história. Constitui-se num retrato da memória que permite à escola rever a sua intencionalidade e sua história. Constitui-se, ainda, em um planejamento que prevê ações (conteúdos, avaliação, funções e relações que se estabelecem dentro da escola e entre a escola e a comunidade) a curto, médio e longo prazos, intervindo diretamente na prática pedagógica. 
Posteriormente à análise dos projetos pedagógicos, foram aplicados questionários com 40 alunos de cursos técnicos do Campus Caucaia, contendo 17 questões em escala de Likert de 5 pontos, envolvendo perguntas sobre a frequência com a que tinham acesso a conteúdo e insumos que facilitassem ou promovessem o contato com conceitos ligados à inovação tecnológica, empreendedorismo e propriedade intelectual.

Por fim, cinco professores responderam a entrevistas semiestruturadas, com tópicos sobre suas opiniões acerca da validade da inclusão de tais temas nas práticas pedagógicas empregadas com alunos de ensino médio técnico, bem como sobre o acesso aos meios necessários para o ensino dessas temáticas, aspectos favoráveis, barreiras e necessidades. As entrevistas foram realizadas na sede do IFCE Campus Caucaia e duraram entre 15 e 30 minutos cada. A abordagem semiestruturada segue o que Ludke e André (1986) defendem como mais adequada para pesquisas em educação.

Parece-nos claro que o tipo de entrevista mais adequado para o trabalho de pesquisa que se faz atualmente em educação aproxima-se mais dos esquemas mais livres, menos estruturados. As informações que se quer obter e os informantes que se quer contatar, em geral professores, diretores, orientadores, alunos e pais, são mais convenientemente abordáveis através de um método mais flexível. (LUDKE; ANDRÉ, 1986, p. 40)

Após a transcrição, as entrevistas foram analisadas segundo os pressupostos teóricos da Análise de Conteúdo, de Bardin (1977), com a abordagem da análise temática. Conforme aponta Laurence Bardin, o método compreende

Um conjunto de técnicas de análise das comunicações visando obter, por procedimentos, sistemáticos e objetivos de descrição do conteúdo das mensagens, indicadores (quantitativos ou não) que permitam a inferência de conhecimentos relativos às condições de produção/recepção (variáveis inferidas) destas mensagens. (BARDIN, 1977, p. 42)

A triangulação dos dados das três etapas gerou proposições que foram comparadas aos resultados de três estudos sobre o ensino de PI no Brasil.

\section{Resultados e Discussão}

A primeira parte do trabalho observou o conteúdo dos projetos pedagógicos de cursos técnicos oferecidos pelo IFCE na Região Metropolitana de Fortaleza (RMF). Para o objetivo deste trabalho, o achado mais importante do levantamento dos projetos pedagógicos dos 16 cursos técnicos de nível médio oferecidos na RMF, foi a completa ausência no texto do termo propriedade intelectual, bem como as insignificantes aparições dos termos invenção, transferência de tecnologia, patente e desenvolvimento tecnológico.

O fato revelou a premência de uma reflexão sobre a necessidade de inclusão ou não de tais temas nos projetos pedagógicos dos cursos. Outra discussão possível é sobre como esse assunto deve ser abordado para o público em questão. Reforçou, ainda, a hipótese de que exista uma lacuna no ensino de PI para este público e que pode ser oferecido, como alternativa, um material didático de apoio para familiarizar os estudantes sobre o assunto. 
Foram encontradas 40 menções ao termo inovação. Contudo, a análise dos textos mostrou que a preocupação com a inovação não está associada a práticas de ensino em sala de aula. O termo apareceu com maior frequência nos textos das justificativas e concepções dos cursos. Esse achado reforçou a necessidade de questionar alunos e professores sobre a presença do tema nas práticas pedagógicas, o que é esclarecido nas seções posteriores deste artigo.

Termo mais recorrente no estudo, "empreendedorismo" apareceu 137 vezes. A palavra surgiu, na maioria das vezes, em um contexto associado à disciplina de empreendedorismo, como matriz curricular, ementa, conteúdo programático e bibliografia sugerida. Um indício de que os alunos recebem de fato conteúdos sobre a matéria.

\subsection{Questionários com Alunos}

Na percepção da maioria dos alunos que responderam aos questionários, o tema inovação está presente em sala de aula. Do total de alunos que responderam, $45 \%$ declararam que o tema é abordado com muita frequência e $40 \%$ frequentemente. O dado é um indício de que o corpo docente aborda a temática, mesmo não estando prevista oficialmente nas ementas de disciplinas dos cursos.

Curiosamente, o percentual de alunos que declarou ter acesso ao tema inovação é superior ao dos que informaram ter acesso ao tema empreendedorismo (25\% para muita frequência e $33 \%$ para frequentemente). A análise dos projetos pedagógicos revelou que todos os cursos contavam com disciplinas de empreendedorismo. $\mathrm{O}$ achado pode ensejar diversas possibilidades de aprofundamento da investigação, entre as quais sobre uma possível insuficiência na abordagem do tema ou se a disciplina deva ser ministrada no início dos cursos.

Gráfico 1 - Frequência da abordagem dos temas inovação, empreendedorismo e PI em sala de aula

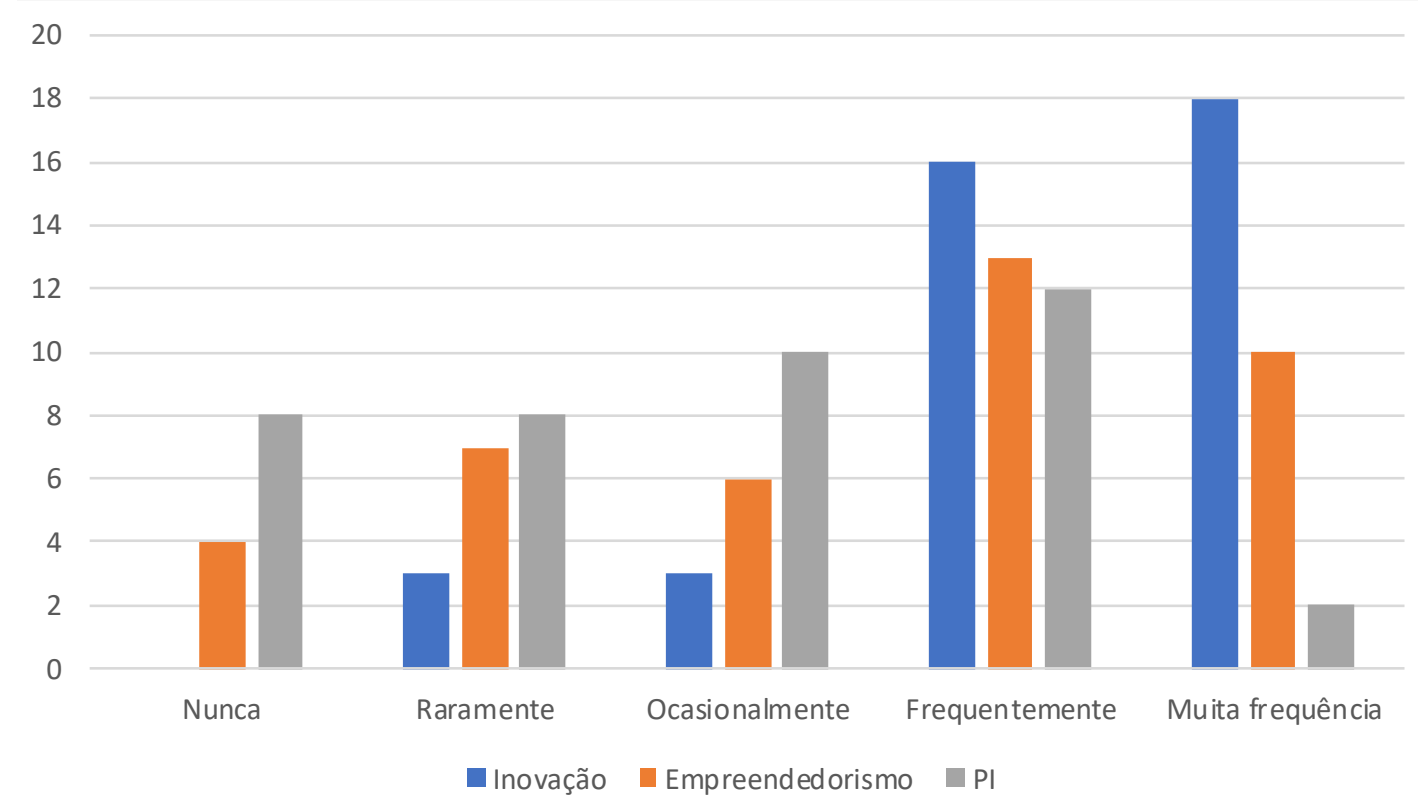

Fonte: Elaborado pelas autoras deste artigo (2020)

Quando questionados sobre formas de proteção da propriedade intelectual, como direito autoral, marcas e patentes, a maioria percebe que esses conceitos nunca, raramente ou oca- 
sionalmente são abordados em sala de aula. A exceção foi o termo marca, que obteve $38 \%$ de respostas para frequentemente e $33 \%$ responderam ocasionalmente.

Esse resultado revela uma contradição. Embora os alunos tenham respondido que o tema propriedade intelectual é abordado em sala de aula (somando-se os que responderam frequentemente e com muita frequência chega-se a $40 \%$ dos respondentes), quando a pergunta é sobre formas de proteção, a percepção é a de que o assunto é pouco abordado nas práticas pedagógicas. É um indício de que o assunto não é tratado de forma suficiente nos cursos.

Nesse aspecto, os dados convergem com a análise dos projetos pedagógicos dos cursos, quando demonstram não haver qualquer menção ao termo propriedade intelectual nos documentos analisados. Mostra similaridade, ainda, com outros estudos que investigaram a temática e que serão abordados na seção Discussão.

Um percentual significativo dos alunos (48\%) relatou ter acesso a materiais didáticos sobre inovação frequentemente, o que não ocorre com empreendedorismo e PI. Para PI, 43\% responderam ter acesso ocasionalmente a materiais didáticos. Já para empreendedorismo, observa-se um equilíbrio nos percentuais de respostas: nunca $18 \%$, raramente $23 \%$, ocasionalmente $23 \%$, frequentemente $20 \%$ e muita frequência $18 \%$.

Com relação à carreira profissional, os cursos parecem não motivar os alunos a seguirem carreiras relacionadas ao universo da inovação e PI. Quando perguntada se deseja no futuro se tornar cientista ou pesquisador, a maioria não concorda nem discorda (53\%). Responderam concordar $23 \%$. Outros 5\% concordam plenamente, enquanto $15 \%$ discordam e $5 \%$ discordam plenamente. Quando perguntada se no futuro pretende ser um inventor, a maioria não concorda e nem discorda (53\%). O percentual dos que discordam (23\%) é superior ao dos que concordam (18\%). A percepção com relação a empreendedorismo é diferente. A maioria (45\%) concorda que pode se tornar no futuro um empreendedor. Um grande percentual (35\%) não concorda e nem discorda.

Gráfico 2 - Frequência da abordagem dos temas marca, direito autoral e patente em sala de aula

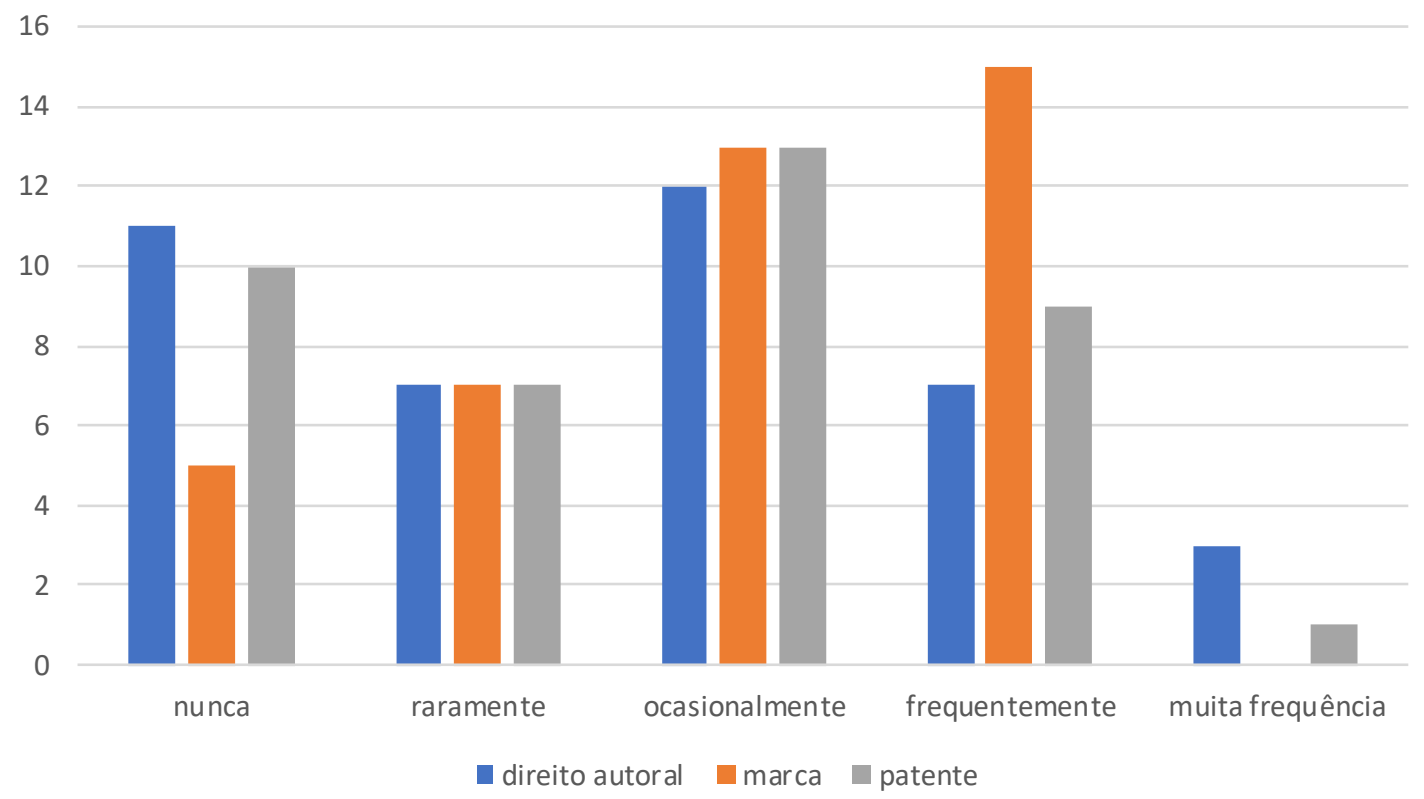

Fonte: Elaborado pelas autoras deste artigo (2020) 


\subsection{Entrevistas com Professores}

A análise de conteúdo das entrevistas resultou em um elenco de 57 unidades temáticas, representadas por núcleos de sentido completo expressos no texto, que podem equivaler a uma resposta inteira ou parte desta. As unidades foram codificadas e classificadas em quatro categorias: Aspectos relacionados aos professores; Aspectos metodológicos; Aspectos relacionados aos alunos; e Aspectos relacionados ao IFCE. Cada uma delas, por sua vez, foi dividida em subcategorias, englobando temáticas diferentes. Para se responder aos objetivos da pesquisa, as unidades de análise foram avaliadas em três critérios: favorabilidades, barreiras e necessidades para o ensino dos conteúdos no nível médio técnico. O resumo das categorias é descrito a seguir.

Quadro 1 - Categorias

\begin{tabular}{|c|c|c|c|}
\hline Categorias & SubCATEGORIAS & $\begin{array}{c}\text { NÚMERO DE UNIDADES } \\
\text { DE ANÁLISE }\end{array}$ & DETALHAMENTO/AVALIAÇÃO \\
\hline \multirow{4}{*}{$\begin{array}{l}\text { Aspectos relacionados } \\
\text { aos professores }\end{array}$} & $\begin{array}{l}\text { Percepção sobre relevância } \\
\text { do ensino de inovação, PI } \\
\text { e Empreendedorismo }\end{array}$ & 11 & 11 favorabilidades \\
\hline & Conflito propedêutica X técnica & 2 & 2 barreiras \\
\hline & $\begin{array}{l}\text { Abordagem ou não do } \\
\text { tema em sala de aula }\end{array}$ & 6 & $\begin{array}{l}4 \text { favorabilidades } \\
\text { e } 2 \text { barreiras }\end{array}$ \\
\hline & Liderança dos professores & 4 & 4 favorabilidade \\
\hline \multirow{2}{*}{ Aspectos metodológicos } & $\begin{array}{l}\text { Necessidade de abordagem } \\
\text { interdisciplinar }\end{array}$ & 3 & $\begin{array}{l}1 \text { favorabilidade e } \\
2 \text { necessidades }\end{array}$ \\
\hline & Metodologias inovadoras & 1 & 1 favorabilidades \\
\hline \multirow{2}{*}{$\begin{array}{c}\text { Aspectos relacionados } \\
\text { aos alunos }\end{array}$} & Conflito ensino médio x técnico & 3 & 3 barreiras \\
\hline & $\begin{array}{l}\text { Desafios para estimular a } \\
\text { juventude para o tema }\end{array}$ & 3 & 2 barreiras e 1 necessidade \\
\hline \multirow{5}{*}{$\begin{array}{l}\text { Aspectos relacionados } \\
\text { ao IFCE }\end{array}$} & Material didático & 5 & $\begin{array}{c}2 \text { barreiras, } 2 \\
\text { favorabilidades } 1 \\
\text { necessidade }\end{array}$ \\
\hline & $\begin{array}{l}\text { Mecanismos de estímulo a } \\
\text { uma cultura de inovação }\end{array}$ & 4 & $\begin{array}{l}2 \text { favorabilidades } \\
2 \text { barreiras }\end{array}$ \\
\hline & Formação continuada & 12 & $\begin{array}{l}11 \text { necessidades e } \\
1 \text { favorabilidade }\end{array}$ \\
\hline & Currículo & 3 & 3 necessidades \\
\hline & Infraestrutura & 1 & 1 barreira \\
\hline
\end{tabular}

Fonte: Elaborado pelas autoras deste artigo (2020)

\subsubsection{Aspectos Relacionados aos Professores}

A categoria "Aspectos relacionados aos professores" engloba uma das subcategorias mais relevantes em número de unidades de análise: "Percepção sobre relevância do ensino de inovação, PI e Empreendedorismo". Essa subcategoria expressa a opinião dos professores acerca da validade ou não do ensino de inovação tecnológica, propriedade intelectual e empreen- 
dedorismo para alunos do nível médio técnico. Todas as 11 unidades de análise encontradas foram classificadas como favorabilidades. Ou seja, o discurso dos cinco professores indica que eles acreditam que é importante o ensino desses temas no nível médio técnico, como se pode observar nos exemplos transcritos abaixo:

Sim, importantíssimo, não só ter o conhecimento da definição, o que é, mas também de como fazer uma patente, da importância de uma patente. Quais são as benesses da patente, como patentear, que órgão procurar, quais legislações estão inseridas em trabalho acerca do desenvolvimento de patentes. Saber os tipos de patentes, porque existem vários tipos. É importante que os meninos saibam disso até mesmo porque são jovens e têm várias ideias e uma ou outra ideia que eles tenham pode sim gerar um produto que possa gerar uma patente (Unidade de análise 2.A).

Bastante. Como nós lidamos com tecnologia, então é essencial essa parte de inovação, empreendedorismo, tem tudo a ver com a parte técnica do curso". (Unidade de análise 1B)

Ainda sobre os "Aspectos relacionados aos professores", é observada uma percepção favorável dos docentes sobre sua liderança e poder de influência como agentes de incentivo a uma cultura de inovação. Entre as barreiras apontadas, está a dicotomia entre propedêtica e técnica. Na visão de alguns professores, os temas inovação, PI e empreendedorismo estão mais presentes nas atividades acadêmicas das áreas técnicas e ausentes entre os professores do campo da propedêutica. Outro aspecto levantado pelos professores é que os assuntos em análise, muitas vezes, são abordados por iniciativa própria dos docentes, visto que não há instrumentos formais que prevejam a inclusão de tais assuntos no conteúdo ministrado.

\subsubsection{Aspectos Metodológicos}

Nesta categoria, os professores revelaram a necessidade de abordagem interdisciplinar dos temas, integrando-os ao conteúdo das demais disciplinas, sobretudo da disciplina empreendedorismo, que já existe nos currículos dos cursos. Essa categoria refletiu, ainda, a prática desejável de incluir metodologias inovadoras em sala de aula com objetivo de instigar os alunos para esse tipo de tema.

\subsubsection{Aspectos Relacionados aos Alunos}

Nesta categoria emergiram duas barreiras apontadas pelos professores ao ensino de inovação e propriedade intelectual. Primeiro, o desafio de chamar a atenção para temas aparentemente distantes da vida dos estudantes. A segunda foi a existência de um conflito entre os alunos, o que repercute no tipo de conteúdo focado pela comunidade acadêmica: dar seguimento aos estudos em busca de uma vaga na universidade ou profissionalizar-se para acessar o quanto antes o mercado de trabalho. Segue um exemplo de conteúdo referente a esse tema:

[...] é um conflito muito grande. A gente tem outras questões que os meninos consideram mais relevantes que é o preparatório para eles entrarem na universidade. Muitos de nossos alunos focam muito nisso porque veem o IF como a única chance deles de conseguir isso. Então é isso que é mais cobrado de nós. Essa preparação para um período da vida deles que é bem peculiar, que eles estão concluindo o ensino básico então na tentativa 
de adentrar ao ensino superior, muitos deles só têm o IF como ferramenta para estar conseguindo estes objetivos deles (Unidade de análise 7D).

\title{
3.2.4 Aspectos Relacionados ao IFCE
}

Esta categoria inclui subcategorias "Material didático", "Mecanismos de estímulo à cultura de inovação", "Formação continuada", "Currículo" e "Infraestrutura". De todas essas subcategorias, a que emergiu com discurso mais recorrente, com 12 unidades de análise, foi "Formação continuada", que se refere às oportunidades oferecidas pelo IFCE para capacitação dos professores nos temas discutidos. No conjunto das 12 unidades de análise encontradas, apenas uma mostrou-se como favorabilidade, indicando a suficiência das capacitações. A grande maioria das menções revela que, embora existam iniciativas para capacitação dos professores, é necessário mais investimento nesse sentido, tal como é demonstrado nos exemplos de resposta elencados a seguir.

\begin{abstract}
É a gente ter formação de professores para isso, porque a formação, ela passa pelos docentes que são eles que estão mais próximos aos estudantes. Não tem como a gente falar de uma formação de determinada área com atividades pontuais ou eventos. Os meninos vão ter conhecimento, contato, mas é um contato muito superficial. Se a gente quiser trabalhar com estes estudantes de maneira mais aprofundada para que eles possam ter propriedade disso, é interessante que se tenha uma formação também dos docentes para que possam saber como trabalhar isso. Perceber que isso é um dos principais desafios, porque a gente não vê isso nas nossas formações nas instituições de onde a gente vem (Unidade de análise 6D).

Olha, já vi algumas oportunidades junto ao próprio instituto, oferecendo, ofertando alguns cursos, mas de uma maneira muito, digamos assim, brotando ainda. Então, foram alguns e-mails, uma oferta, surgiu essa possibilidade de se trabalhar com o tema de propriedade intelectual, uma capacitação, faz tempo e foi algo vago (Unidade de análise 9B).
\end{abstract}

Ainda entre os aspectos relacionados ao IFCE, foram apontadas como necessidades a inclusão dos assuntos no currículo, a disponibilidade de material didático sobre o assunto $e$ infraestrutura. Os professores afirmaram ainda que o IFCE contribui para a formação de uma cultura de inovação, embora possa melhorar, a exemplo do discurso a seguir:

De forma geral, a impressão que tenho, ele ainda contribui de forma modesta, apesar de ser significante se pensar no todo. O IFCE tem uma parcela significante, mas acho poderia ser bem maior que ela é hoje (Unidade de análise 7C).

\subsection{Triangulação de Dados}

Ao se triangular os resultados encontrados nas análises dos projetos pedagógicos, nos questionários dos alunos e nas entrevistas com os professores, emergem as seguintes proposições:

a) Embora o assunto inovação não esteja presente nos projetos pedagógicos associado efetivamente às atividades das disciplinas, a percepção dos alunos é a de que o assunto 
está presente em suas práticas pedagógicas. Esse resultado converge com o discurso dos professores que consideraram o tema inovação relevante para alunos do ensino médio técnico. Pode ser um indicativo de que os professores, sobretudo das áreas técnicas, incluam assuntos relacionados à inovação em suas práticas pedagógicas, mesmo não constando nos currículos.

b) O tema mais recorrente na análise de conteúdo das entrevistas com professores referiu-se à necessidade de capacitação para docentes nos temas inovação e propriedade intelectual, com 12 unidades de análise, sendo 11 necessidades e uma favorabilidade.

c) Quando questionados sobre formas de proteção da PI, como direito autoral, marcas e patentes, a maioria dos alunos percebe que esses conceitos são pouco ou ocasionalmente abordados em sala de aula. A exceção foi o termo marca, que obteve $38 \%$ de respostas para frequentemente e $33 \%$ respostas para ocasionalmente. O fato converge com a análise dos projetos pedagógicos que não cita, em momento algum, o termo propriedade intelectual. Converge, ainda, com o discurso dos professores que revelam necessidade de formação para docentes na temática, necessidade de inclusão do assunto nos currículos e de material didáticos para que os conteúdos possam, de fato, chegar aos alunos.

d) A análise dos projetos pedagógicos dos cursos demonstra o termo "empreendedorismo" presente 137 vezes nos documentos, em sua maioria, em um contexto associado à disciplina de empreendedorismo, como matriz curricular, ementa, conteúdo programático e bibliografia sugerida. Contudo, quando questionados se o tema é abordado em sala de aula, o percentual dos alunos que afirmaram que raramente é abordado chegou a $18 \%$. Outros $10 \%$ afirmaram nunca e $15 \%$ que ocasionalmente o tema é assunto dos cursos. $O$ dado merece estudo complementar para elucidação dos fatores que podem ter contribuído para essa percepção dos alunos.

e) Entre as barreiras apontadas pelos professores para o ensino dos temas estão aspectos relacionados ao conflito entre o ensino médio tradicional e técnico, conflito entre disciplinas propedêuticas e técnicas, desafios de estimular o jovem para o tema, ausência de material didático, carência de mecanismos de estímulo a uma cultura de inovação e carência de infraestrutura.

De uma forma geral, os resultados da pesquisa convergiram com outros estudos que buscaram avaliar o conhecimento de estudantes sobre o tema. Pesquisa realizada por Gimenez, Bonaccelli e Carneiro (2012) observou que a Unicamp, instituição que ocupa a segunda posição no ranking dos maiores depositantes de pedidos de patentes no Brasil, depende de iniciativas individuais dos professores para o ensino de PI, em vez de uma orientação mais geral da universidade.

A conclusão é semelhante à observada no IFCE Campus Caucaia. Se por um lado observa-se a ausência de previsão do ensino de PI nos Projetos Pedagógicos, por outro, os professores demonstram entender que a temática é importante, por isso sugerem haver iniciativas de ensino por conta dos próprios docentes.

O estudo de Gimenez, Bonaccelli e Carneiro (2012) verificou palavras-chaves relacionadas à PI nos sistemas acadêmicos para análise das disciplinas oferecidas nos cursos de graduação, pós-graduação e extensão universitária. Em seguida, no estudo, eles realizaram entrevistas com professores responsáveis por esses cursos e disciplinas. 
Os autores observaram a área de graduação como o espaço mais amplo para o ensino da PI, pois há potencialmente mais oportunidades para os estudantes terem algum contato com o conteúdo. A cobertura no âmbito da pós-graduação é pequena e no âmbito da extensão é insignificante, considerando o número total de cursos em cada área.

Para os autores do estudo, os dados confirmam o diagnóstico feito pela OMPI em vários países de que a propriedade intelectual ainda não é difundida no currículo dos cursos de graduação, pós-graduação e extensão. O estudo realizado no IFCE Campus Caucaia, por sua vez, complementa esse diagnóstico, demonstrando que também em uma unidade de ensino profissional o assunto não é difundido no currículo.

Embora a cultura da Propriedade Intelectual tenha crescido e as políticas públicas tenham se ampliado sobre esse tema, ele ainda não aparece como algo consolidado, longe disso. Segundo o entendimento da maioria dos entrevistados, o tratamento dado à Unicamp ainda precisa evoluir de várias maneiras, principalmente no que se refere à tomada de decisões, por parte da liderança da universidade, para organizar ações mais efetivas em torno desse problema (GIMENEZ; BONACCELLI; CARNEIRO, 2012, p. 187)

Os resultados sinalizam que também no IFCE, assim como na Unicamp, os esforços para implementar ações de inovação, como laboratórios, polo de inovação e mestrado em propriedade intelectual, não impactaram suficientemente o ensino da temática no nível técnico. O levantamento realizado no IFCE abriu a perspectiva para que se avalie maneiras de se estimular a oferta de conteúdo na temática.

Um outro estudo semelhante foi realizado por Lamana e Franscisco (2014) em um curso técnico em Eletromecânica do Centro Estadual de Educação Profissional de Ponta Grossa no Paraná. A pesquisa observou que menos de $40 \%$ dos alunos entrevistados demonstraram saber o que é propriedade intelectual. Os autores consideram urgente fomentar a educação escolar em PI e defenderam o desenvolvimento de recursos humanos focados na temática.

$\mathrm{O}$ estudo, que consistiu em questões fechadas aplicadas aos discentes e aos docentes, revelou que embora $70 \%$ dos professores tenham declarado ter conhecimento de propriedade intelectual, quando questionados sobre as formas de proteger o conhecimento, apenas metade dos que declararam ter conhecimento sobre PI responderam ter conhecimento sobre como proteger estes direitos. Entre os alunos que conhecem o tema, apenas $20 \%$ declararam conhecer as formas de proteger o direito de propriedade intelectual.

O resultado é similar ao observado no estudo de caso do IFCE Campus Caucaia. Embora $40 \%$ dos alunos tenham declarado ter acesso ao conteúdo de propriedade intelectual frequentemente e com muita frequência, os estudantes revelaram conhecer pouco as formas de proteção da PI.

Lamana e Franscisco (2014) acreditam ser possível inserir o assunto nos conteúdos de disciplinas técnicas e consideram apropriado o ensino por meio de projetos, palestras, minicursos, semanas e jogos. Para intervir na situação, sugerem reformulação curricular ou até mudança do projeto pedagógico da escola estudada. Essa conclusão vai ao encontro da análise de conteúdo das entrevistas semiestruturadas com os professores do IFCE. Eles recomendam a formação de professores, a inclusão de material didático e até a inclusão do assunto nos currículos. 
Outro estudo que reforça a estratégia de inserir o ensino de PI no ensino técnico foi realizado por Cavalcanti e Bemfica (2019), ao analisar estratégia para disseminação da propriedade intelectual no Sistema Pernambucano de Inovação (SPIn).

Após examinar o documento Estratégia de Ciência, Tecnologia e Inovação para Pernambuco 2017-2022 (ECT\&I-PE), os autores apresentaram propostas com linhas de ações de disseminação do conhecimento. Eles propuseram, ainda, como forma de estimular o desenvolvimento de talentos e criatividade, a realização de ações de disseminação para os jovens de escolas técnicas do estado, seguindo o modelo japonês. Recomendaram, também, a produção de material didático com linguagem adequada sobre PI específica para alunos do ensino fundamental $e$ médio da rede pública do estado.

A adoção desse tipo de modelo pode ser considerada uma rota possível, mas, para isso, faz-se necessário uma avaliação com objetivo de observar a adequação às características da população em questão.

\section{Considerações Finais}

A pesquisa demonstrou que o Instituto Federal do Ceará (IFCE) é uma instituição com atuação ativa em inovação tecnológica e que os alunos do IFCE Campus Caucaia têm a percepção de que o tema inovação é abordado nas práticas educacionais.

O estudo demonstrou, ainda, que os professores consideram relevante a inclusão dos temas inovação, propriedade intelectual e empreendedorismo nas atividades educativas. Demonstrou, também, que os professores consideram necessário um maior investimento na capacitação do corpo docente para melhorar os níveis das atividades. $\mathrm{O}$ exame dos projetos pedagógicos dos cursos técnicos oferecidos pelo Instituto Federal do Ceará na Região Metropolitana de Fortaleza indica a ausência de preocupação com a Propriedade Intelectual ou a Inovação nas práticas pedagógicas.

De uma forma geral, os resultados da pesquisa convergiram com outros estudos que buscaram avaliar o conhecimento de estudantes sobre o tema. O levantamento realizado no IFCE enseja pistas de que se possa avaliar maneiras de se estimular a oferta de conteúdo na temática. Uma possível intervenção é o estímulo à formação dos professores, o investimento em eventos escolares e a edição de materiais didáticos. O trabalho abre perspectiva para a realização de novas pesquisas qualitativas que abordem o nível de contato dos corpos docente e discente com as temáticas

\section{Referências}

AMORIM-BORHER, M. B. et al. Ensino e Pesquisa em Propriedade Intelectual no Brasil. Revista Brasileira de Inovação, Rio de Janeiro, v. 6, n. 2, p. 281-310, maio, 2007. Disponível em: https:// periodicos:sbu:unicamp:br/ojs/index:php/rbi/article/view/8648949. Acesso em: 17 nov. 2019.

ARAÚJO, G. G. de et al. Produção de Patentes no Estado do Ceará: um estudo comparativo entre as instituições públicas. Cadernos de Prospecção, Salvador, v. 4, n. 11, p. 966-982, 2018. Disponível em: https://portalseer:ufba:br/index:php/nit/article/view/27131. Acesso em: 17 nov. 2019. 
BARDIN, Laurence. Análise de conteúdo. Lisboa: Edições 70, 1977.

BRASIL. Lei n. 9.394/96, de 20 de dezembro de 1996. LDB. Brasília, DF, 20 dez. 1996. Disponível em: http://www.planalto.gov.br/ccivil_03/leis/19394.htm. Acesso em: 29 maio 2019.

BRASIL. Lei n. 13.243/2016. Dispõe sobre estímulos ao desenvolvimento científico, à pesquisa, à capacitação científica e tecnológica e à inovação, janeiro 2016. Disponível em: http:// www:planalto:gov:br/ccivil_03/_Ato2015-2018/2016/Lei/L13243:htm. Acesso em: 3 jun. 2019.

CAVALCANTI, A. M.; BEMFICA, E. A. Disseminação da Propriedade Intelectual como Estratégia para Políticas de Ciência, Tecnologia e Inovação: o caso do Sistema Pernambucano de Inovação (SPIn). Cadernos de Prospecção, Salvador, v. 12, n. 1, p. 15-30, março, 2019.

DE NEGRI, Fernanda. Novos caminhos para a inovação no Brasil. Washington, DC: Wilson Center, 2018. 159p.

FARIA, A. X. de. O Ensino da Propriedade Intelectual nos Cursos de Graduação do Brasil: Razões e Proposições. 2011. 110p. Dissertação (Mestrado Profissional em Propriedade Intelectual e Inovação) - Instituto Nacional de Propriedade Industrial, Rio de Janeiro, 2011.

GIL, A. C. Métodos e Técnicas de Pesquisa Social. 6. ed. São Paulo: Atlas, 2008.199p.

GIMENEZ, A. M. N.; BONACCELLI, M. B. M.; CARNEIRO, A. M. The Challenges of Teaching and Training in Intellectual Property. Journal of Technology Management \& Innovation, Santiago, Chile, p. 176-188, nov. 2012. Disponível em: https://scielo:conicyt:cl/scielo:php?pid=S0718$27242012000400014 \&$ script=sci_arttext\&tlng=em. Acesso em: 16 nov. 2019.

INPI - INSTITUTO NACIONAL DA PROPRIEDADE INDUSTRIAL. Cooperação entre os escritórios de PI do BRICS. 2019. Disponível em: http://www:ipbrics:org/index:html. Acesso em: 10 nov. 2019.

KRUGLIANSKAS, I.; MATIAS-PEREIRA, J. Um enfoque sobre a Lei de Inovação Tecnológica do Brasil. Revista de Administração Pública, Rio de Janeiro, v. 39, n. 5, p. 1.011-1.029, 2005. Disponível em: http://bibliotecadigital:fgv:br/ojs/index:php/rap/article/view/6577/5161. Acesso em: 15 nov. 2019.

LAMANA, S.; FRANSCISCO, A. C. de. O Ensino de Propriedade Intelectual nas Escolas Técnicas. In: IV SIMPÓSIO NACIONAL DE ENSINO DE CIÊNCIA E TECNOLOGIA. Ponta Grossa: [s.n.], 2014, SINECT. Anais [...]. Ponta Grossa, PR, 2014. Disponível em: http://www:sinect:com:br/anais2014/. Acesso em: 16 nov. 2019.

LUDKE, Menga; ANDRÉ, Marli E. D. A. Pesquisa em Educação: abordagens qualitativas. São Paulo: Epu, 1986.

LONGHI, Simone Raquel Pagel; BENTO, Karla Lucia. O político-pedagógico: uma ação coletiva. Revista de Divulgação Técnico-Científica do ICPG, [s.l.], v. 3. n. 9, jul.-dez, 2006.

MORE: Mecanismo Online para Referências, versão 2.0. Florianópolis: UFSC Rexlab, 2013. Disponível em: http://www.more.ufsc.br/. Acesso em: 4 jun. 2019.

OMPI - ORGANIZAÇÃO MUNDIAL DA PROPRIEDADE INTELECTUAL. Índice Global de Inovação 2019: Índia registra grandes avanços, enquanto Suíça, Suécia, EUA, Países Baixos e Reino Unido lideram a classificação. 2019. Disponível em: https://www.wipo.int/export/sites/www/ pressroom/pt/documents/pr_2019_834.pdf. Acesso em: 15 nov. 2019. 
PROEN/IFCE (Fortaleza). IFCE em Números. 2020. Disponível em: http://ifceemnumeros.ifce.edu. br/. Acesso em: 22 mar. 2020.

PROFNIT - PROGRAMA DE PÓS-GRADUAÇÃO EM PROPRIEDADE INTELECTUAL E TRANSFERÊNCIA DE TECNOLOGIA PARA A INOVAÇÃO. Rede PROFNIT. 2020. Disponível em: http://www.profnit.org.br/pt/sample-page/. Acesso em: 6 jun. 2020.

TAKAGI, Y.; ALLMAN, L.; SINJELA, M. A. Teaching of Intellectual Property: Principles and Methods. Nova York: Cambridge University Press, 2008. 333p.

WIPO - WORLD INTELLECTUAL PROPERTY ORGANIZATION (Suiça). (ed.). Teaching Intellectual Property (IP) in Countries in Transition. Genebra: Wipo - World Intellectual Property Organization, 2013. 100p. Disponível em: https:/www.wipo.int/edocs/pubdocs/en/wipo pub_transition_7.pdf. Acesso em: 10 nov. 2019.

\section{Sobre as Autoras}

\section{Verônica Maria Vasconcelos Freire}

E-mail: veronica.freire@embrapa.br

Mestre em Propriedade Intelectual e Transferência de Tecnologia para a Inovação pelo PROFNIT/IFCE em 2020.

Endereço profissional: Rua Doutora Sara Mesquita, n. 2.270, Pici, Fortaleza, CE. CEP: 60511-110.

\section{Joelia Marques de Carvalho}

E-mail: joeliamarquesc@gmail.com

Doutora em Ciência de Alimentos pela Universidade Federal do Ceará em 2015.

Endereço profissional: Instituto Federal de Educação Ciência e Tecnologia do Ceará, Campus Caucaia, Rua Francisco da Rocha Martins, Pabussu, Caucaia, CE. CEP: 61609-090. 